\title{
Gut Microbiota and Pediatric Disease
}

\section{Valerio lebba $^{\mathrm{b}}{\text { Marina } \text { Aloi }^{\mathrm{a}} \text { Fortunata Civitelli }}^{\mathrm{a}}$ Salvatore Cucchiara ${ }^{\mathrm{a}}$}

a Pediatric Gastroenterology and Liver Unit, Department of Pediatrics, and ${ }^{b}$ Microbiology Unit, Department of

Public Health Sciences, Sapienza University of Rome, Rome, Italy

\section{Retraction Statement See Next Page}




\section{Retraction Statement}

The Editor and Publisher of the Journal Digestive Diseases wish to state that the following article has been retracted from the Journal due to plagiarized parts:

Gut Microbiota and Pediatric Disease

Iebba V, Aloi M, Civitelli F, Cucchiara S

Dig Dis 2011;29:531-539 (DOI: 10.1159/000332969) 